\title{
It is time to talk about people: a human-centered healthcare system
}

\author{
Meghan M Searl ${ }^{1,2^{*}}$, Lea Borgi ${ }^{3}$, Zeina Chemali ${ }^{2,4}$
}

\begin{abstract}
Examining vulnerabilities within our current healthcare system we propose borrowing two tools from the fields of engineering and design: a) Reason's system approach [1] and b) User-centered design [2,3]. Both approaches are human-centered in that they consider common patterns of human behavior when analyzing systems to identify problems and generate solutions. This paper examines these two human-centered approaches in the context of healthcare. We argue that maintaining a human-centered orientation in clinical care, research, training, and governance is critical to the evolution of an effective and sustainable healthcare system.
\end{abstract}

\section{Introduction}

With healthcare reform in the spotlight there exists a window of opportunity to identify weaknesses in our healthcare system and propose workable solutions. At the present time, few would argue that the U.S. Healthcare system functions optimally. There are many reasons for this, including the fragmenting effect of competing interests in the health marketplace with insufficient incentives for building and maintaining systems that knit these fragments together. While the full list of reasons goes beyond the scope of this paper, one critical weakness to understand is that the U.S. Healthcare system at the present time is not inherently humancentered. That is, on many levels, the current healthcare system is not designed for optimal use by human beings. It is when human tendencies are ignored that opportunities for error become insidious.

We propose that a robust and sustainable healthcare system must be human-centered. Efforts to build and rebuild parts of the system in a human-centered fashion require reliable tools. Two of these tools that are currently underutilized in the area of healthcare are a) Reason's system approach [1] and b) User-centered design $[2,3]$. As a call for more human-centered approaches to optimizing healthcare delivery, we review these two approaches, using a variety of examples to illustrate both real and potential applications.

\footnotetext{
* Correspondence: msearl@partners.org

'Brigham \& Women's Hospital, 221 Longwood Ave., Boston, MA 02115, USA
} Full list of author information is available at the end of the article

\section{Two human-centered tools}

In his studies of safety, James Reason made a critical distinction between two ways of understanding why human errors occur: the person approach and the system approach [1]. While the person approach blames the individual most closely linked to the error, the system approach takes into account all of the many contributing factors that played a role in the manifestation of the error.

As a part of the system approach, Reason proposed the "Swiss cheese" model to explain why system failures occur [4]. In this model he suggests that in complex systems, failures are prevented from occurring much of the time because of a variety of barriers that serve as checks and balances. In most systems, however, these barriers have areas of weakness. When a series of weaknesses align, a hole in the system appears such that barriers no longer exist to prevent failure and a breakdown occurs. Latent errors refer to weaknesses in the system that, when combined with relevant stressors, contribute to active failures. Active failures are the unsafe acts committed by people who are in direct contact with the patient or system [4].

According to Reason, "The basic premise in the system approach is that humans are fallible and errors are to be expected, even in the best organizations." What is so striking about this model is that it provides a framework for viewing people as vulnerable, rather than inherently faulty. Reason explicitly acknowledges the existence of identifiable vulnerabilities within and outside of each person that give rise to errors when those 
vulnerabilities are aligned. So, in this constructive, human-centered approach, he neutralizes any implicit blame by saying that "even the best organizations" are fallible.

While Reason's system approach is a top-down method for analyzing problems, user-centered design is a bottom-up method for developing solutions. The term 'user-centered design' was coined by Donald Norman and became widely adopted after he published UserCentered System Design: New Perspectives on HumanComputer Interaction in 1986 and then The Psychology Of Everyday Things in 1988 [2,3]. User-centered design, of which human-centered design is a specific instance, is a technique used in the field of engineering that prioritizes the relevant characteristics of a product user throughout the design of a product.

Taking the example of designing an automobile dashboard, a user-centered designer would spend a great deal of time in the proverbial shoes of the future driver, trying to understand his needs (What pieces of information does he need to monitor while driving?), preferences (Would he like to have the current radio station displayed at eye level?) and limitations (How many pieces of information can he process simultaneously?), among other things. Like Reason's system approach, user-centered design starts with the assumption that all users have basic need and limitations and that it is the designer's responsibility to understand, anticipate, and design in accordance with these needs and limitations [3].

The system approach has only recently been applied to the field of healthcare, despite successful use in other fields, including engineering, mining, nuclear power, and aviation [5]. One reason for this delayed application is the fact that most hospitals grew in direct response to social needs, without priority being given to top-down design [6]. That is, hospitals were not viewed like factories, which were often built with attention to questions of efficiently and safety. Use of system-level analyses may have also lagged behind because of the default assumption that efficiency and safety would not merit careful attention, related to the stereotype that health care professionals, and physicians in particular, are perfect [5].

After a series of egregious errors that caught the attention of healthcare professionals, the media, and the public, it became clear that something needed to be done to address the issue of patient safety [7]. In 1999, Institutes of Medicine (IOM) published a powerful report entitled, "To Err is Human," which fueled an already growing shift from viewing errors as problems of individuals to problems of systems. However, even in light of this shift, there remains a long history of a culture of blame and shame that held single individuals responsible for negative outcomes [8-10]. Active efforts will likely be required to achieve a complete shift in perspective and, in the view of some, the shift may never be complete [11-13].

Like Reason's system approach, user-centered design is also relatively new to healthcare and has been applied only to a limited degree. According to Zhang, a Health Information Technologist, "In healthcare...the culture is still to train people to adapt to poorly designed technology, rather than to design technology to fit people's characteristics" [14]. This failure of widespread adoption of user-centered design methods occurs, even despite requests for its application in a number of areas, including the development of interactive health technologies for patients $[15,16]$. Devito Dabbs cites the following possible reasons for the lagging adoption of usercentered methods by those in healthcare: lack of appreciation for the importance of usability testing, lack of time and resources to devote to upfront research and development, limited expertise in the principles and techniques of user-centered design, and the tendency to develop information health technologies based on developer-driven needs and priorities rather than those of the intended users [17].

Next we will explore the ways in which the system approach and user-centered design have been applied.

\section{A System Approach to Healthcare: Allowing for Human Nature}

An eminently practical consequence of examining error with a system approach is the ability to generalize analyses to large groups of people. Whereas a person approach assumes that errors result largely from uniquely personal failures, the system approach suggests that the errors stem from identifiable patterns or tendencies, either within human beings in general or in the system's environment. The next section will outline some of the findings from this and other areas of research that illuminate relevant aspects of human behavior.

\section{Predictably irrational: People have systematic cognitive biases}

The fields of cognitive psychology and behavioral economics, among others, have taught us that human beings are much less rational than they appear on the surface [18-20]. Yet the field of medicine has developed, in large part, as if healthcare providers, and diagnosticians in particular, were entirely rational beings. In recent years, the role of cognitive biases in medical education and training has gained some attention [21], though on the whole there still exists a relative underappreciation of these cognitive biases among attending and trainees alike $[22,23]$. Some of the most common 
systematic information processing biases include:

- Anchoring: the tendency to overvalue (anchor) one piece of information when making a decision. For example, patients insufficiently adjust their subjective risk to the objective risk value communicated by healthcare providers [20,24-26].

- Authority bias: the tendency to overvalue the opinion of a perceived authority and undervalue one's own judgment in comparison. Studies have demonstrated that physicians sometimes tend to overvalue so-called expert opinions, in lieu of using critical analysis [25-27].

- Availability heuristic: making an estimate according to how easily an example can be brought to mind, while discounting more relevant information. Some studies have shown that diagnostic error can be influenced by this heuristic [25,26,28-30].

- Base rate fallacy: when available statistical data (base rates) are ignored in favor of one's own hypothesis [20].

- Confirmation bias: the tendency to search for or interpret information in a way that confirms one's preconceptions [31,32].

- Framing: interpreting a situation using a narrow lens [25,26,33-35].

- Fundamental attribution error: the tendency to over-emphasize personality variables while underemphasizing situational variables to explain specific behaviors [36,37].

- Hindsight bias: the inclination to see past events as if they had been predictable without acknowledging that all of the relevant information had not been available at the time [38].

- Illusory correlation: an erroneous conclusion about an association that seems real but does not actually exist $[39,40]$.

- In-group bias: the tendency for people to give preferential treatment to others they perceive to be members of their own groups [41,42].

- Overconfidence effect: excessive confidence in one's own answers to questions. An example of this is the finding that physicians, and particularly those in training, underestimate their own errors and overestimate the errors of their colleagues, even when errors in judgment are pointed out to them $[22,43,44]$.

- Premature closure: the tendency to jump to a conclusion prior to having all of the relevant information, typically in order to escape the experience of doubt and uncertainty [45]

- Representativeness heuristic: coming to a conclusion based on how much a hypothesis resembles available data. While this is helpful in making quickly decisions in everyday life, it can result in neglect of relevant base rates [20,25,26,46].

- Stereotyping: when one expects a member of a group to have certain characteristics solely because of group membership, not because of individual characteristics [42].

\section{Shame and Blame: People hide their errors in punitive environments}

Healthcare providers are reluctant to report their own errors in a system fraught with risk and blame that relies on tort law as a major regulatory force. One of the consequences of Tort law and financial markets being significant regulatory forces in the absence of non-punitive, transparent error reporting mechanisms is that clinicians and healthcare delivery systems have become reluctant to report errors, thus perpetuating high risk levels and failing to integrate corrective feedback into the system.

Clinicians are unlikely to respond to increased pressure to report within this climate, and would be more responsive to a culture that emphasizes safety and encourages learning over shaming. Learning cultures facilitate detection and sharing of errors, reflection upon and understanding of underlying causes, proactive involvement in professional life, and increased dedication to improving safety [47].

In an ideal world, clinicians would speak openly about their mistakes. Senior staff would be viewed as role models, secure about reporting and learning from their own errors. Asking for and receiving support would be encouraged and viewed as a strength rather than a weakness. Safety cultures would be strongly endorsed by top-down organizational policies and promoted by leaders as best practices.

\section{Physicians on a pedestal: Social power structures in healthcare}

The field of medicine has been traditionally hierarchical in nature. In any hierarchical system, those with less power often find that challenging or making requests of those with more power can come at a cost. Not surprisingly, this is true in healthcare settings. As a result, when faced with the question of whether to challenge more powerful individuals, the less powerful individuals must decide which costs to incur-those resulting from a challenge or from withholding potentially corrective feedback [48]. For example, interrupting a physician by a page to report an error is a burden on physicians, who, in turn, can easily disregard the corrective feedback or not assimilate the seriousness of the error during the translation of the order into action. Correcting a charismatic physician may also lead to consequences 
that no one is ready to endure (e.g. pressure on the job, alienation from other members of the team, delay in promotion etc.). The result of this dynamic is that the people with less power are less likely to identify their own errors for fear of criticism or retribution, thus planting the seed of a closed loop system where little can be learned.

\section{Risks and benefits of teamwork: Bringing out the best and the worst}

A team includes people working together to achieve shared goals. Effective teams share resources, communicate clearly, and coordinate their efforts to adapt to change [49]. Observational studies and retrospective analyses have shown that flawed teamwork rather than lack of clinical skills is a major contributor in the occurrence of errors $[49,50]$. Effective communication is the cornerstone around which a team is built; it should be done with trust and understanding and without fear of hierarchy. On the contrary, a leader should flatten the power distance and facilitate speaking up [51].

In healthcare, teamwork relies heavily on communication and coordination. Although healthcare providers may perceive quality of teamwork differently, they share a mental model that becomes essential to their teamwork [52]. No matter what the outcomes of new training programs, heightened public awareness and accuracy in timely diagnosis turn out to be, clinicians need to be empowered by their successful achievements as a team and supported by their organizations when they make mistakes [53]. Leadership styles that value contribution from staff will promote a climate where the information is shared in a timely manner, effectively and openly. In addition, this leadership style will increase staff wellbeing [54]. A healthy, happier staff is one that can shift flexibly between implicit coordination (during routine condition) and explicit coordination (during critical intervention) to ensure the highest level of patient safety [55].

\section{The fallacy of the health belief model: Knowing and doing are different things}

Over the past 40 years advances in health psychology have demonstrated that humans often engage in behaviors that they well know to be dangerous or unhealthy. This means that health education alone, while certainly important, is likely to be insufficient to trigger behavior change. Yet, this is still the primary means of attempting to elicit behavior change in provider-patient relationships. The traditional role of the all-knowing and allpowerful physician) sets forth the implicit message, "I know what is best. I tell you (the patient) what to do and you conform." There was very little room for incorporating the experience of the patient into early models of healthcare delivery. Similarly, early health behavior change theories (e.g. Health Belief Model) assumed that if people were educated about health promoting behaviors and about consequences of high-risk behaviors, they wouldn't do them. We now recognize that human behavior is driven by a complex set of interacting variables, only one of which is knowledge about what is best for one's health $[56,57]$. Many of the more recent health behavior change models take more humancentered approaches that make allowances for what are now known to be common errors in logic and responses to emotional, physical, and environmental cues that distract from one's health goals. However, many elements of our current healthcare delivery systems are still founded on the premise of the less human-centered health belief model.

\section{Coping with uncertainty: The ultimate challenge}

In his studies of human error, Reason found that uncertainty in one's environment or understanding of one's goals was a significant factor that contributed to making errors [58]. Studies of misdiagnosis have found that diagnostic uncertainty increases the likelihood that an incorrect diagnosis will be made [59]. Patients do not help in correcting the process as they also struggle in the face of uncertainty, are fearful or too trusting of authority figures [22]. In a nutshell, while the diagnostic process requires robustness and flexibility to deal with the uncertainty of not knowing or not knowing enough, physicians remain not trained nor do they tolerate uncertainty hence committing mistakes. Frequently patients will simply leave the care of a physician with whom they are dissatisfied and go elsewhere searching for certain answers. Given inadequate feedback, physicians may think that patients are not coming to the clinic because they are cured while, in truth, patients may have simply preferred not to return.

\section{User-Centered Design in Healthcare: A Promising Start}

Early applications of user-centered design were seen primarily in medical engineering, health information management, and web design [60-63]. Safety-oriented analyses and solutions have been at the forefront of user-centered applications in healthcare, with such examples as bar-code technology [64] and checklists [65]. User-centered approaches to the study and development of provider tools have also expanded into more traditional areas of health research, including care coordination [66], data entry interface design $[67,68]$, cognitive processes engaged during healthcare procedures $[69,70]$, patient monitoring tools [71], and development of screening tools $[72,73]$.

Similarly, user-centered research focused on patients has grown over the last few years, primarily in 
development of e-health education tools [74-76], and interactive e-health technologies $[17,77,78]$.

Despite the promise of these emerging areas of research and practice, when considering the scope of all ongoing research, program development, and health technology innovation within the U.S. healthcare system, user-centered design is found only in a very small proportion of work being done. There are still many problems within the area of healthcare that require application of a user centered approach, including standardization of self-care tools, development of assessment and treatment tools for emotional health, chronic care tools, and preventative care systems. This paper is a call for shifting user-centered design toward the mainstream of work in these areas.

\section{Future applications of the system approach}

While a system approach to understanding errors in healthcare has played a critical role in shifting from a Culture of Blame to a Culture of Safety, significantly more work is yet to be done in understanding the psychological and behavioral drivers of healthcare providers, patients, and other members of the system, such as family members, administrators, and those responsible for building and maintaining equipment and systems. The role of psychological defense mechanisms is not well understood and likely plays an important role in predicting areas of vulnerability for all members of the healthcare system. At the same time, a system approach to understanding how to harness and cultivate the strengths of different parts of the system is equally important to study and has been given less attention than patterns of vulnerability and weakness [79].

\section{Future applications of a human-centered approach}

One of the most critical areas of healthcare requiring a human-centered approach is the development of standardized reporting mechanisms that, through open feedback loops, allow for the reporting of and learning from medical errors. Some of the benefits of applying a humancentered approach to the development of a safety reporting system include: an emphasis on understanding and learning over blame, attention to the existing vulnerabilities in the system, design focused on motivating people to report, an emphasis on iterative improvements, and a place for a participatory research component.

A number of Patient Safety Reporting Systems(PSRS) have emerged since 1999 with the goal of providing such mechanisms of feedback. Some are government sponsored entities, such as the PSRS developed by the VA system and NASA in 2000 and others are privately organized, most often founded by industry, professional or consumer groups.

The Patient Safety and Quality Improvement Act of 2005 is a landmark piece of legislation that provides
Federal legal privilege and confidentiality protections to information reported in reference to patient safety concerns. It developed out of the recognition that, despite the importance of reporting for the purpose of learning about how and why errors occur, many healthcare providers would naturally be reluctant to report their own errors for fear of retribution. Prior to the passing of this act, studies had demonstrated that granting immunity to personnel reporting errors voluntarily would have a positive impact on the reporting incidence of errors [80].

In a non-punitive, learning culture, punishment and humiliation are replaced by an emphasis on trust and positive change. These elements are critical for maintenance and promotion of a safety culture. When healthcare professionals feel that they can report their errors without losing their jobs and reputation or fear of litigation, they will be more likely to cooperate with a root cause analysis approach to identifying and understanding errors [81].

Other areas that would benefit from application of a human-centered approach include:

- Training in social dynamics: Integrating knowledge of social dynamics into training of healthcare professionals and into routine team practices would be useful in creating a widespread understanding of human tendencies.

- Accounting for patient biases: The average patient cannot be expected to pursue positive health behaviors based only on knowledge of healthy and unhealthy behaviors. Rather, integration of education with techniques that account for known biases (e.g., motivational interviewing, behavioral economics, etc) may prove more effective in increasing the health activation levels of patients.

- Accounting for clinician biases: Awareness of and compensation for clinician biases can be addressed through peer consultation and application of reflective practices that incorporate knowledge of one's strengths and limitations.

- Building resilience: Resilience refers to the degree to which a system continuously prevents, detects, mitigates or ameliorates hazards or incidents leading to bounce back to its original ability to provide core functions following the occurrence of adverse events [82]. Taking action to reduce risk and prevent the reoccurrence of the same or incident improves system resilience [82].

\section{Conclusion: A sustainable solution must be human-centered at every level}

An understanding of human thought processes, emotions, and behaviors needs to guide the design of 
healthcare delivery systems. We would be wise to apply what we know about human tendencies to build healthcare systems that optimize both patient behaviors and clinician behaviors. The more we know about how people naturally work best, the more we can leverage that to address the current problems related to patient safety [79]. All users of the healthcare system can benefit from this type of approach. Our paper is an open invitation to an overdue discussion about placing human beings in the center of our thinking about healthcare. We maintain that robust research and training efforts focused on the issues described in this paper will be critical for the evolution of a sustainable healthcare system.

\section{Author details}

'Brigham \& Women's Hospital, 221 Longwood Ave., Boston, MA 02115, USA. ${ }^{2}$ Harvard Medical School, 25 Shattuck St., Boston, MA 02115, USA. ${ }^{3}$ St. Elizabeth's Hospital, 736 Cambridge St., Boston, MA 02135, USA.

${ }^{4}$ Massachusetts General Hospital, 55 Fruit St., Boston, MA 02114, USA.

\section{Authors' contributions}

All authors were instrumental in the development of the initial concepts and the writing of the manuscript. All authors read and approved the final manuscript.

\section{Competing interests}

The authors declare that they have no competing interests.

Received: 1 February 2010 Accepted: 26 November 2010 Published: 26 November 2010

\section{References}

1. Reason JT: Human error Cambridge England; New York: Cambridge University Press; 1990.

2. Norman DA: The psychology of everyday things New York: Basic Books; 1988.

3. Norman DA, Draper SW: User centered system design: new perspectives on human-computer interaction Hillsdale, N.J.: L. Erlbaum Associates; 1986.

4. Reason J: Human error: models and management. BMJ 2000, 320:768-770.

5. Karsh B-T, Alper SJ: Work system analysis: the key to understanding health care systems. In Advances in Patient Safety: From Research to Implementation. Volume 2. Rockville, MD: Agency for Healthcare Research and Quality; 2005:337-348.

6. Leape LL: A systems analysis approach to medical error. J Eval Clin Pract 1997, 3:213-222

7. Millenson ML: Pushing the profession: how the news media turned patient safety into a priority. Qual Saf Health Care 2002, 11:57-63.

8. Larson EB: Measuring, monitoring, and reducing medical harm from a systems perspective: a medical director's personal reflections. Acad Med 2002, 77:993-1000

9. Cox PM Jr, D'Amato S, Tillotson DJ: Reducing medication errors. Am J Med Qual 2001, 16:81-86

10. Meaney M: From a culture of blame to a culture of safety-the role of institutional ethics committees. Bioethics Forum 2001, 17:32-42.

11. Collins ME, Block SD, Arnold RM, Christakis NA: On the prospects for a blame-free medical culture. Soc Sci Med 2009, 69:1287-1290.

12. Khatri $\mathrm{N}$, Brown GD, Hicks LL: From a blame culture to a just culture in health care. Health Care Manage Rev 2009, 34:312-322.

13. Cohen MM, Eustis MA, Gribbins RE: Changing the culture of patient safety: leadership's role in health care quality improvement. Jt Comm J Qual Saf 2003, 29:329-335.

14. Zhang J: Human-centered computing in health information systems. Part 1: analysis and design. J Biomed Inform 2005, 38:1-3.

15. Institute of Medicine (U.S.): Committee on Quality of Health Care in America. Crossing the quality chasm: a new health system for the 21st century Washington, D.C.: National Academy Press; 2001.
16. Gustafson DH, Robinson TN, Ansley D, Adler L, Brennan PF: Consumers and evaluation of interactive health communication applications. The Science Panel on Interactive Communication and Health. Am J Prev Med 1999, 16:23-29.

17. Dabbs Ade V, Myers BA, Mc Curry KR, Dunbar-Jacob J, Hawkins RP, Begey A, Dew MA: User-centered design and interactive health technologies for patients. Comput Inform Nurs 2009, 27:175-183.

18. Ariely D: Predictably irrational: the hidden forces that shape our decisions. 1 edition. New York, NY: Harper; 2008.

19. Thaler RH, Sunstein CR: Nudge: improving decisions about health, wealth, and happiness New Haven: Yale University Press; 2008.

20. Tversky A, Kahneman D: Judgment under Uncertainty: Heuristics and Biases. Science 1974, 185:1124-1131.

21. Regehr G, Norman GR: Issues in cognitive psychology: implications for professional education. Acad Med 1996, 71:988-1001.

22. Berner ES, Graber ML: Overconfidence as a cause of diagnostic error in medicine. Am J Med 2008, 121:S2-23.

23. Wu AW, Folkman S, McPhee SJ, Lo B: Do house officers learn from their mistakes? JAMA 1991, 265:2089-2094.

24. Senay I, Kaphingst KA: Anchoring-and-adjustment bias in communication of disease risk. Med Decis Making 2009, 29:193-201.

25. Vickrey BG, Samuels MA, Ropper AH: How neurologists think: A cognitive psychology perspective on missed diagnoses. Ann Neurol 2010, 67:425-433.

26. Redelmeier DA: Improving patient care. The cognitive psychology of missed diagnoses. Ann Intern Med 2005, 142:115-120.

27. Woolf SH, Kamerow DB: Testing for uncommon conditions. The heroic search for positive test results. Arch Intern Med 1990, 150:2451-2458.

28. Oppenheimer DM: Spontaneous discounting of availability in frequency judgment tasks. Psychol Sci 2004, 15:100-105.

29. Tversky A, Kahneman D: Availability: a heuristic for judging frequency and probability. Cognitive Psychology 1973, 5:207-232.

30. Salem-Schatz SR, Avorn J, Soumerai SB: Influence of clinical knowledge, organizational context, and practice style on transfusion decision making. Implications for practice change strategies. JAMA 1990, 264:476-483.

31. Croskerry P: The importance of cognitive errors in diagnosis and strategies to minimize them. Acad Med 2003, 78:775-780.

32. Wason PC: Reasoning about a rule. Q J Exp Psychol 1968, 20:273-281.

33. Tversky A, Kahneman D: The framing of decisions and the psychology of choice. Science 1981, 211:453-458.

34. Cartmill RS, Thornton JG: Effect of presentation of partogram information on obstetric decision-making. Lancet 1992, 339:1520-1522.

35. McNeil BJ, Pauker SG, Sox HC Jr, Tversky A: On the elicitation of preferences for alternative therapies. N Engl J Med 1982, 306:1259-1262.

36. Hineline PN: A self-interpretive behavior analysis. Am Psychol 1992, 47:1274-1286.

37. Ross L: The intuitive psychologist and his shortcomings: Distortions in the attribution process. In Advances in experimental social psychology. Volume 10. Edited by: Berkowitz L. New York: Academic Press; 1977.

38. Fischoff B, Beyth R: I knew it would happen: Remembered probabilities of once-future things. Organizational Behavior and Human Performance 1975, 13:1-16.

39. Van Rooy D, Van Overwalle F, Vanhoomissen T, Labiouse C, French R: A recurrent connectionist model of group biases. Psychol Rev 2003, 110:536-563.

40. Chapman LJ, Chapman JP: Genesis of popular but erroneous psychodiagnostic observations. J Abnorm Psychol 1967, 72:193-204.

41. Tajfel H: Cognitive aspects of prejudice. J Biosoc Sci 1969, Suppl 1: 173-191.

42. Brewer M: In-group bias in the minimal intergroup situation: A cognitivemotivational analysis. Psychological Bulletin 1979, 86:307-324.

43. Fischoff B, Slovic P, Lichtenstein S: Knowing with certainty: The appropriateness of extreme confidence. Journal of Experimental Psychology: Human Perception and Performance 1977, 3:552-564.

44. Berner ES, Maisiak RS, Heuderbert GR, Young KR Jr: Clinician performance and prominence of diagnoses displayed by a clinical diagnostic decision support system. AMIA Annu Symp Proc 2003, 76-80.

45. McSherry D: Avoiding premature closure in sequential diagnosis. Artif Intell Med 1997, 10:269-283. 
46. Payne VL, Crowley RS: Assessing the use of cognitive heuristic representativeness in clinical reasoning. AMIA Annu Symp Proc 2008, 571-575.

47. Hoff T, Pohl H, Bartfield J: Implementing Safety Cultures in Medicine: What We Learn by Watching Physicians. Advances in Patient Safety 2003, 1:15-38.

48. Sutcliffe KM, Lewton E, Rosenthal MM: Communication failures: an insidious contributor to medical mishaps. Acad Med 2004, 79:186-194.

49. Manser T: Teamwork and patient safety in dynamic domains of healthcare: a review of the literature. Acta Anaesthesio/ Scand 2009, 53:143-151.

50. Powell SM: Creating a systems approach to patient safety through better teamwork. Biomed Instrum Technol 2006, 40:205-207.

51. Leonard M, Graham S, Bonacum D: The human factor: the critical importance of effective teamwork and communication in providing safe care. Qual Saf Health Care 2004, 13(Suppl 1)::85-90.

52. Mathieu JE, Heffner TS, Goodwin GF, Salas E, Cannon-Bowers JA: The influence of shared mental models on team process and performance. $J$ Appl Psychol 2000, 85:273-283.

53. Graber ML: Taking steps towards a safer future: measures to promote timely and accurate medical diagnosis. Am J Med 2008, 121:S43-46.

54. Sluiter JK, Bos AP, Tol D, Calff M, Krijnen M, Frings-Dresen MH: Is staff wellbeing and communication enhanced by multidisciplinary work shift evaluations? Intensive Care Med 2005, 31:1409-1414.

55. Entin EE, Serfaty D: Adaptive Team Coordination. Human Factors 1999, 41:312-325.

56. Leventhal $H$, Weinman J, Leventhal EA, Phillips LA: Health Psychology: the Search for Pathways between Behavior and Health. Annu Rev Psychol 2008, 59:477-505.

57. Prochaska JO, DiClemente CC: Stages of change in the modification of problem behaviors. Prog Behav Modif 1992, 28:183-218.

58. Reason J: Safety in the operating theatre - Part 2: human error and organisational failure. Qual Saf Health Care 2005, 14:56-60

59. Chowdhury FA, Nashef L, Elwes RD: Misdiagnosis in epilepsy: a review and recognition of diagnostic uncertainty. Eur J Neurol 2008, 15:1034-1042.

60. Rinkus S, Johnson-Throop KA, Zhang J: Designing a knowledge management system for distributed activities: a human centered approach. AMIA Annu Symp Proc 2003, 559-563.

61. Jones J, Harris M, Bagley-Thompson C, Root J: Development of usercentered interfaces to search the knowledge resources of the Virginia Henderson International Nursing Library. AMIA Annu Symp Proc 2003, 884.

62. Kinzie MB, Cohn WF, Julian MF, Knaus WA: A user-centered model for web site design: needs assessment, user interface design, and rapid prototyping. J Am Med Inform Assoc 2002, 9:320-330.

63. Campbell R, Ash J: Comparing bedside information tools: a usercentered, task-oriented approach. AMIA Annu Symp Proc 2005, 101-105.

64. Poon EG, Keohane CA, Yoon CS, Ditmore M, Bane A, Levtzion-Korach O, Moniz T, Rothschild JM, Kachalia AB, Hayes J, et al: Effect of bar-code technology on the safety of medication administration. $N$ Engl J Med 2010, 362:1698-1707

65. Haynes AB, Weiser TG, Berry WR, Lipsitz SR, Breizat AH, Dellinger EP, Herbosa T, Joseph S, Kibatala PL, Lapitan MC, et al: A surgical safety checklist to reduce morbidity and mortality in a global population. $N$ Engl J Med 2009, 360:491-499.

66. Behkami NA, Dorr DA: User centered design in complex healthcare workflows: the case of care coordination and care management redesign. AMIA Annu Symp Proc 2009, 2009:39-43.

67. Kreis C, Gorman P: Word frequency analysis of dictated clinical data: a user-centered approach to the design of a structured data entry interface. Proc AMIA Annu Fall Symp 1997, 724-728.

68. Johnson CM, Johnson TR, Zhang J: A user-centered framework for redesigning health care interfaces. J Biomed Inform 2005, 38:75-87.

69. DeShazo JP, Turner AM: An interactive and user-centered computer system to predict physician's disease judgments in discharge summaries. J Biomed Inform 2010, 43:218-223.

70. Nemeth C, O'Connor M, Klock PA, Cook R: Discovering Healthcare Cognition: The Use of Cognitive Artifacts to Reveal Cognitive Work Organization Studies 2006, 27:1011-1035.
71. Gao T, Kim MI, White D, Alm AM: Iterative user-centered design of a next generation patient monitoring system for emergency medical response. AMIA Annu Symp Proc 2006, 284-288.

72. Taylor DP, Bray BE, Staggers N, Olson RJ: User-centered development of a Web-based preschool vision screening tool. AMIA Annu Symp Proc 2003, 654-658.

73. Xie Z, Suki D, Graham S, Sawaya R: Design a usable protocol screening database: the user-centered approach. AMIA Annu Symp Proc 2005, 1161

74. Atkinson NL, Saperstein SL, Desmond SM, Gold RS, Billing AS, Tian J: Rural eHealth nutrition education for limited-income families: an iterative and user-centered design approach. J Med Internet Res 2009, 11:e21.

75. Catarci T, De Giovanni L, Gabrielli S, Kimani S, Mirabella V: Scaffolding the design of accessible eLearning content: a user-centered approach and cognitive perspective. Cogn Process 2008, 9:209-216.

76. Bae J, Wolpin S, Kim E, Lee S, Yoon S, An K: Development of a usercentered health information service system for depressive symptom management. Nurs Health Sci 2009, 11:185-193.

77. Glasgow RE, Christiansen S, Smith KS, Stevens VJ, Toobert DJ: Development and implementation of an integrated, multi-modality, user-centered interactive dietary change program. Health Educ Res 2009, 24:461-471.

78. Arsand E, Demiris G: User-centered methods for designing patient-centric self-help tools. Inform Health Soc Care 2008, 33:158-169.

79. Braithwaite J, Runciman WB, Merry AF: Towards safer, better healthcare: harnessing the natural properties of complex sociotechnical systems. Qual Saf Health Care 2009, 18:37-41.

80. Wilf-Miron R, Lewenhoff I, Benyamini Z, Aviram A: From aviation to medicine: applying concepts of aviation safety to risk management in ambulatory care. Qual Saf Health Care 2003, 12:35-39.

81. Rex JH, Turnbull JE, Allen SJ, Vande Voorde K, Luther K: Systematic root cause analysis of adverse drug events in a tertiary referral hospital. $J$ Comm J Qual Improv 2000, 26:563-575.

82. Sherman $H$, Castro $G$, Fletcher M, Hatlie M, Hibbert $P$, Jakob R, Koss $R$, Lewalle $P$, Loeb J, Perneger $T$, et al: Towards an International Classification for Patient Safety: the conceptual framework. Int J Qual Health Care 2009, 21:2-8.

doi:10.1186/1478-4505-8-35

Cite this article as: Searl et al:: It is time to talk about people: a humancentered healthcare system. Health Research Policy and Systems 2010 8:35.

\section{Submit your next manuscript to BioMed Central and take full advantage of:}

- Convenient online submission

- Thorough peer review

- No space constraints or color figure charges

- Immediate publication on acceptance

- Inclusion in PubMed, CAS, Scopus and Google Scholar

- Research which is freely available for redistribution 